\title{
Structural, Optical and Magnetic Properties of YIG Doped with Erbium and Terbium Nanofilms using Sol-Gel Method
}

\author{
Suleiman M. Elhamali, N.B. Ibrahim* and S.Radiman \\ School of Applied Physics, Faculty of Science and Technology, Universiti Kebangsaan Malaysia, Bangi, Malaysia \\ Email: baayah@ukm.edu.my
}

\begin{abstract}
The combined substitution of $\mathrm{Tb}$ and Er ions at the yttrium site with a formula $\mathrm{Y}_{3-\mathrm{x}-\mathrm{y}} \mathrm{Tb}_{\mathrm{x}} \mathrm{Er}_{\mathrm{y}}$ $\mathrm{Fe}_{5} \mathrm{O}_{12},(\mathrm{x}=0.0,0.2)$ and $(\mathrm{y}=0.0,0.2,0.6,1.0$ and 1.4$)$ were prepared by a sol-gel method. The crystalline structures of all films were found to have a pure single phase garnet structure. This result confirmed the successful incorporation of erbium and terbium ions into YIG structure. The lattice constant increased linearly with $\mathrm{Er}^{+3}$ concentrations from 12.379 to $12.532 \AA$. The morphology measurement revealed the formation of nanoparticles films. The magnetic properties characterization exhibited that all films are soft ferrimagnetic materials. The results showed the saturation magnetization Ms of pure YIG at $150\left(\mathrm{emu} / \mathrm{cm}^{3}\right)$. The Ms value decreased to $110 \mathrm{emu} / \mathrm{cm}^{3}$ at concentration of $(\mathrm{x}=0.2, \mathrm{y}=0.0)$, then increased with increment of $(\mathrm{y})$ content in a linear manner. The optical transparency of films was over $96 \%$ at $(\mathrm{y}=0.6)$ in the wavelength range of 600 to $900 \mathrm{~nm}$. At a short wavelength $(\lambda<400 \mathrm{~nm})$, absorption coefficient $\alpha$ increased linearly with increment of $\mathrm{Er}^{3+}$ ions. Because of nearly zero absorption coefficient in the NIR region, the films could be useful as optical isolator.
\end{abstract}

Keywords: Nanoparticles, Sol-gel preparation, Er, Tb - substituted YIG, Magnetic properties.

\section{Introduction}

Yttrium iron garnet (YIG) has low-coercivity, high-remanence, and low conductivity, making them suitable for microwave operation [1-3]. Garnet has complicated structure consists of three crystallographic sites:

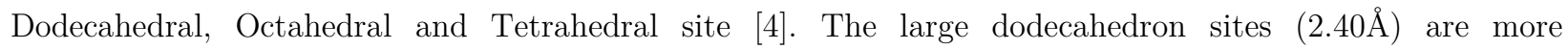
appropriate for large radii ions such as $\mathrm{Bi}^{3+}, \mathrm{Y}^{3+}$ or other rare earth ions, whereas the octahedron (2.01 $\AA$ ) and tetrahedron sites $(1.87 \AA)$ are more suitable for a smaller one, such as $\mathrm{Al}^{3+}, \mathrm{Ga}^{3+}$ and $\mathrm{Fe}^{3+}[5-7]$. In Yttrium iron garnet $\left(\mathrm{Y}_{3} \mathrm{Fe}_{5} \mathrm{O}_{12}\right)$, non-magnetic $\mathrm{Y}^{3+}$ ions are located on the dodecahedral 24(c) sites while magnetic $\mathrm{Fe}^{3+}$ ions occupy the tetrahedral 24(d) sites and the octahedral 16(a) sites in a ratio of 3:2. As the $\mathrm{Fe}^{3+}$ ions sit on crystallographically non-equivalent sites, they form two different magnetic sublattices with antiferromagnetic interactions $\mathrm{Fe}^{3+}{ }_{\text {tet }}(\downarrow)-\mathrm{O}^{2-}-\mathrm{Fe}^{3+}{ }_{\text {oct }}(\uparrow)$ leading to spontaneous magnetization. This interaction will be stronger when the interionic $\mathrm{Fe}^{3+}-\mathrm{O}^{2-}$ distance are small and the $\mathrm{Fe}^{3+}{ }_{\text {tet }}(\downarrow)-\mathrm{O}^{2-}-$ $\mathrm{Fe}^{3+}{ }_{\text {oct }}$ bond angle is close to a straight angle $\left(180^{\circ}\right)[8,9]$.

The garnet structure is compliant with many substitutions which would lead to different application needs. Recently, many reports have been done in substituting $\mathrm{Bi}^{3+}, \mathrm{Ce}^{3+}$ or other rare earth $(\mathrm{R})$ ions with $\mathrm{Y}^{3+}$ and replacement of $\mathrm{Fe}^{3+}$ ions by $\mathrm{Al}^{3+}$ and $\mathrm{Ga}^{3+}$ ions [10-16]. The substitution of terbium ions into garnet crystal at high content is restricted due to the large ionic radius of terbium compared with yttrium ions. It is found that $\mathrm{Tb}$ content of less than 0.8 restrains the $\mathrm{Y}$ ions to occupy the octahedral sites which may lead to distortion of lattice parameter [17-19]. Therefore, in this study, Tb content is chosen at $\mathrm{x}=0.2$.

Double substitution into yttrium iron garnet (YIG) is an extremely powerful method from a technological applications' point of view to enhance the physical properties of garnet materials, however the number of studies in this field, is limited [20-23]. This study concentrates on combined substitution of $\mathrm{Tb}^{3+} \mathrm{and}^{3+}$ 
ions at the yttrium site. They are chosen for their high verdet constant, beside that larger values of Bohr magneton $\left(9.59 \mu \mathrm{B}\right.$ for $\mathrm{Tb}^{3+}$ and $9.72 \mu \mathrm{B}$ for $\left.\mathrm{Er}^{3+}\right)$ [24]. Therefore, nanoparticles films with the formula of $\mathrm{Y}_{3-\mathrm{x}-\mathrm{y}} \mathrm{Tb}_{\mathrm{x}} \mathrm{Er}_{\mathrm{y}} \mathrm{Fe}_{5} \mathrm{O}_{12}(\mathrm{x}=0.0,0.2)$ and $(\mathrm{y}=0.0,0.2,0.6,1.0$ and 1.4) were prepared. This study is first time reported here for the best of our knowledge to acquire a further comprehension about the effect of double dopant of erbium and terbium into YIG structure on structural, magnetic and optical properties of obtained films. The sol -gel method is chosen as a suitable approach for synthesis, being an inexpensive and producing good-quality garnet film [25].

\section{Experimental Method}

Stoichiometric mixtures of Yttrium (III) $\mathrm{Y}\left(\mathrm{NO}_{3}\right)_{3} \cdot 6 \mathrm{H}_{2} \mathrm{O}$ and Iron(III) $\mathrm{Fe}\left(\mathrm{NO}_{3}\right)_{3} \cdot 9 \mathrm{H}_{2} \mathrm{O}$ were dissolved in $2 \mathrm{~mL}$ of 2-methaoxythanol, then stirred by magnetic stirrer at 15 hours. The Y-Fe solution were refluxed at $80 \pm$ $2{ }^{\circ} \mathrm{C}$ at $3 \mathrm{hr}$. The terbium (III), Tb $\left(\mathrm{NO}_{3}\right)_{3} .5 \mathrm{H}_{2} \mathrm{O}$ and erbium (III), $\mathrm{Er}\left(\mathrm{NO}_{3}\right)_{3} .5 \mathrm{H}_{2} \mathrm{O}$ were dissolved separately in $2 \mathrm{ml}$ of acetic acid, then stirred for $3 \mathrm{hr}$ before adding gradually to Y-Fe solution. Then, the mixture solutions were refluxed at $80 \pm 2{ }^{\circ} \mathrm{C}$ for $3 \mathrm{hr}$. The resulting solution was stirred for two days in order to obtain a homogenous gel. The quartz substrate was heated at $75 \pm 2{ }^{\circ} \mathrm{C}$ for 1 minute before the deposition process to enhance the adhesion of films on substrates. To obtain the film, $20 \mu \mathrm{L}$ of gel was put on quartz glass and spin coated at $500 \pm 3 \mathrm{rpm}$ for $15 \mathrm{sec}$, then at $3500 \pm 5 \mathrm{rpm}$ for $30 \mathrm{sec}$. The films were annealed at $900^{\circ} \mathrm{C}$ in the air for $2 \mathrm{hr}$ at a heating rate of $4^{\circ} \mathrm{C} / \mathrm{min}$ to produce crystalline films.

The crystallographic properties were analyzed by X-ray diffractometer (XRD) using CuKa radiation $(\lambda=0.15406 \mathrm{~nm})$. The obtained peaks were compared according to the reference spectrum of pure YIG card number: (01-073-1377). A field emission scanning electron microscopy (FE-SEM; ZEISS Supra 55VP) was used for surface morphology and to measure the film thickness. An Energy dispersive X-ray spectroscopy (EDX) which was coupled with the FE-SEM was used for elements analysis. An (UV-Vis) spectrophotometer (PerkinElmer-Lambda 950) was used to measure the optical properties in the wavelength range of 190 to $1000 \mathrm{~nm}$. A vibrating Sample Magnetometer (VSM) with a maximum magnetic filled of 6,000 Oe was used for in-plane magnetic measurements at room temperature $\left(\sim 29^{\circ} \mathrm{C}\right)$.

\section{Result and Discussion}

\subsection{Structure Characterizations}

The crystalline structure (see Figure 1) reveals that all films have a pure cubic garnet structure without any secondary phases. The annealing temperature at $900^{\circ} \mathrm{C}$ is adequate to obtain the single phases of the cubic garnet structure of these films. The positions of the main peak (420) are slightly shifted to higher diffraction angles as illustrated in Table .1 . This shift is evidence of change in lattice constant and confirmed that $\mathrm{Tb}^{+3}$ and $\mathrm{Er}^{+3}$ ions have been introduced into YIG structure. To calculate the values of the lattice constant (a), Bragg's equation combined with d-spacing expression of the cubic cell was used [26].

$$
a=\left(\lambda^{2} \beta / 4 \sin ^{2} \theta\right)^{1 / 2}
$$

where $\beta=\left(h^{2}+k^{2}+l^{2}\right),(h, k, L)$ are the Miller indices, $\lambda=0.15406 \mathrm{~nm}$ and $\theta$ is the diffraction angle of $\mathrm{X}$ ray. Bradley \& Jay's extrapolation function is used to minimize the effect of systematic errors [27, 28]. Figure 2 shows the dependence of lattice parameter on the content of $\mathrm{Er}^{+3}$ ions. The lattice constant (a) increases linearly with the increment of $(\mathrm{y})$ contents. It is attributed to the differences in ionic radii of $\mathrm{Y}$ 
$(1.015 \AA), \operatorname{Er}(1.00 \AA)$ and $\mathrm{Tb}(1.04 \AA)$ ions which occupy the dodecahedral sites [29]. Similar results have been reported by Ftema et al. [17] for $\mathrm{Tb}_{0.8} \mathrm{Y}_{2.2} \mathrm{Al}_{\mathrm{y}} \mathrm{Fe}_{5-\mathrm{Y}} \mathrm{O}_{12},(0 \leqslant \mathrm{y} \leqslant 1)$ films. The crystallite sizes were computed using Scherrer's equation according to the XRD line broadening of the main peak (420).

$$
D_{(h, k, l)}=k \lambda / \beta \cos \theta
$$

where $\mathrm{D}_{(\mathrm{h}, \mathrm{k}, \mathrm{l})}$ is the average crystalline size in $\mathrm{nm}, \mathrm{k}$ is the shape factor $(0.89), \lambda$ is the wave length of X-ray, $\beta$ is the half maximum - line width (FWHM) and $\theta$ is diffraction angle. The results are tabulated in Table1. It changes slightly with the increment of y content.

Table 1. Summary of results from XRD measurements at different y content.

\begin{tabular}{cccc}
\hline Content $(\mathrm{y})$ & $2 \ominus\left(^{\circ}\right)$ at $(420)$ line & Lattice constant $(\AA)$ & Crystallite size $(\mathrm{nm})$ \\
\hline 0.0 & 32.415 & 12.379 & 22 \\
0.2 & 32.472 & 12.412 & 24 \\
0.6 & 32.473 & 12.525 & 28 \\
1.0 & 32.474 & 12.532 & 23 \\
1.4 & 32.501 & 12.545 & 25 \\
\hline
\end{tabular}
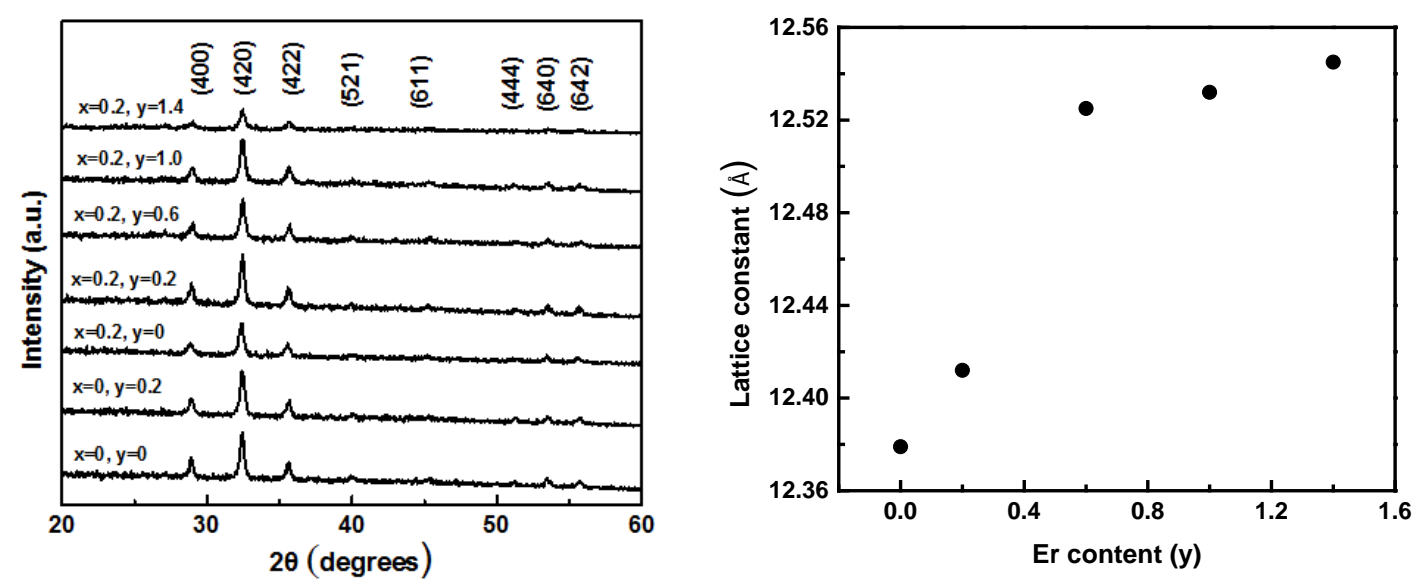

Figure 1. XRD patterns of $\mathrm{Y}_{3-\mathrm{x}-\mathrm{y}} \mathrm{Tb}_{\mathrm{x}} \mathrm{Er}_{\mathrm{y}} \mathrm{Fe}_{5} \mathrm{O}_{12}$ films. Figure 2. The variation of lattice constant with Er content.

\subsection{Magnetic Characterizations}

The paramagnetic contributions of bare substrates were deducted from total magnetization of deposited films. Figure 3(a) shows the in-plane $\mathrm{M}-\mathrm{H}$ hysteresis loops of obtained films. The hysteresis loop with normal shape and low coercivity as illustrated in figure 3(b) reveals that all films are soft magnetic materials. The pure YIG ( $\mathrm{x}=0, \mathrm{y}=0)$ exhibits saturation magnetization, $\mathrm{M}_{\mathrm{s}}$ of $150 \mathrm{emu} / \mathrm{cm}^{3}$ which is higher than the $\mathrm{M}_{\mathrm{s}}$ of bulk YIG (138.3 $\left.\mathrm{emu} / \mathrm{cm}^{3}\right)$ [30] and close to the film prepared using the PLD method on GGG substrate reported by Kehlberger $(144 \pm 7 \mathrm{KA} / \mathrm{m})$ [12]. As mentioned above, $\mathrm{Fe}^{+3}$ ions in a-site and dsite are anti-parallel coupled, leaving a net moment of $\mathrm{Fe}^{+3}$ ions in d-site and therefore the $\mathrm{M}_{\mathrm{s}}$ value of YIG is given mainly from d-site. On the other hand, in this study some $\mathrm{Tb}^{+3} \& \mathrm{Er}^{+3}$ ions are substituted for $\mathrm{Y}^{+3}$ at c-sites at $\mathrm{Y}_{3-\mathrm{x}-\mathrm{y}} \mathrm{Tb}_{\mathrm{x}} \mathrm{Er}_{\mathrm{y}} \mathrm{Fe}_{5} \mathrm{O}_{12}$ formula. Both $\mathrm{Er}^{+3} \& \mathrm{~Tb}^{+3}$ ions prefer the c- sites due to large ionic radii 
[31]. The $\mathrm{Tb}^{+3}$ ions doped YIG reduce the saturation magnetization $\mathrm{M}_{\mathrm{s}}$ from 150 to $110 \mathrm{emu} / \mathrm{cm}^{3}$ (see Figure 3(a)). This reduction in the $\mathrm{M}_{\mathrm{s}}$ value, compared to pure YIG, can be explained by the magnetic moment of the $\mathrm{Tb}^{3+}$ ions that coupled antiparallel with the resultant magnetic sublattices of $\mathrm{Fe}^{3+}$ ions. Ftema et al. have also reported that doping $\mathrm{Y}^{3+}$ with $\mathrm{Tb}^{3+}$ reduce the $\mathrm{M}_{\mathrm{s}}$ value of YIG film, due to the same reason [17]. Similar behavior had been observed when $\mathrm{Er}^{3+}$ ions was doped into YIG, the $\mathrm{M}_{\mathrm{s}}$ value is decreased from 150 to $140 \mathrm{emu} / \mathrm{cm}^{3}$ (see Figure 3(a)). Ramadan et al. have reported that the $\mathrm{M}_{\mathrm{s}}$ value of Er doped YIG films decreases with the increment of $\mathrm{Er}^{3+}$ which due to the $\mathrm{Er}^{3+}$ ions that coupled antiferromagnetically with the resultant magnetic sublattices of $\mathrm{Fe}^{3+}$ ions [32]. However, when $\mathrm{Er}^{3+}$ was doped into $\mathrm{Y}_{3-\mathrm{x}} \mathrm{Tb}_{\mathrm{x}} \mathrm{Fe}_{5} \mathrm{O}_{12}$, the $\mathrm{M}_{\mathrm{s}}$ increases with increasing of the content (Er) by linear manner (see Figure 4). Nevertheless, our results show that increasing the $\mathrm{Er}^{3+}$ in $\mathrm{Y}_{3-\mathrm{x}} \mathrm{Tb}_{\mathrm{x}} \mathrm{Fe}_{5} \mathrm{O}_{12}$ increases the $\mathrm{M}_{\mathrm{s}}$ values, explaining that the $\mathrm{Er}^{3+}$ ion could be coupled ferromagnetically with the resultant magnetic sublattices of $\mathrm{Fe}^{3+}$ ions. Hence, the magnetic structure of such mixed garnet could be understood according to the cation distribution as $\left\{Y_{3-x-y}^{+3} \overline{\mathrm{Er}_{y}^{+3}} \overline{\mathrm{Tb}_{x}^{+3}}\right\}\left[\overrightarrow{F e^{+3}}\right]\left(\overrightarrow{\mathrm{Fe}^{+3}}\right)$. The $\mathrm{Er}^{+3}$ ions which have a large magnetic moment $(9.72 \mu \mathrm{B})$ in c-sites align parallel to the net $\mathrm{Fe}^{+3}$ ions moment in d-sites [33]. Thus the saturation magnetization increased. The difference in ion coupling has also been reported for $\mathrm{Gd}^{3+}$ doped YIG. Aoki et al. have reported that $\mathrm{Gd}^{3+}$ could be aligned ferromagnetically with $\mathrm{Fe}^{3+}$ ions in the d-site of Ce:Gd-YAIG nanocrystal, resulting increased in $\mathrm{M}_{\mathrm{s}}$ values as the $\mathrm{Gd}^{3+}$ ion increases for their Ce:Gd-YAIG nanocrystal [34]. However, Xu et al. have reported that $\mathrm{Gd}^{3+}$ ions align antiferromatically with $\mathrm{Fe}^{3+}$ ions in the d-site of Ce:Gd-YIG, resulting decrease in $\mathrm{M}_{\mathrm{s}}$ values as the $\mathrm{Gd}^{3+}$ ion increases, for their Ce:Gd-YIG samples [23].

The coercivity $\left(\mathrm{H}_{\mathrm{c}}\right)$ for all Er contents $(\mathrm{y})$ exhibited a slight increment and in the range from 21 to 27.5 Oe (see Figure 4). The coercivity are affected by the grain size as shown in Figure 5 . The $\mathrm{H}_{\mathrm{c}}$ value becomes smaller as the grain size increases. Therefore, the obtained results agree with the theory that the coercivity of small particle $\left(H_{c}\right)$ is inversely proportional to grain size according to the relation: $H_{c} \sim 1 / D^{v}$ where $D$ is the particle diameter and $v$ is constant [35].
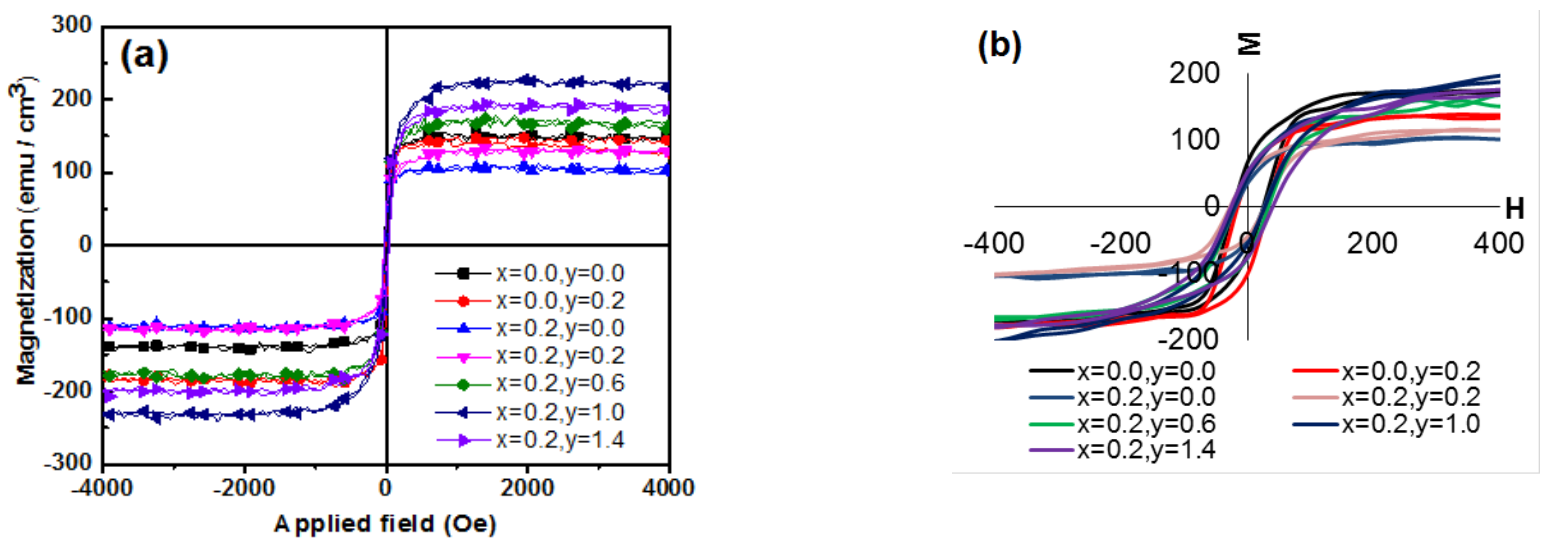

Figure 3. (a) The in- plane M-H hysteresis loops of $\mathrm{Y}_{3-\mathrm{x}-\mathrm{y}} \mathrm{Tb}_{\mathrm{x}} \mathrm{Er}_{\mathrm{y}} \mathrm{Fe}_{5} \mathrm{O}_{12}$ films and (b) shows the hysteresis loop with normal shape and low coercivity. 


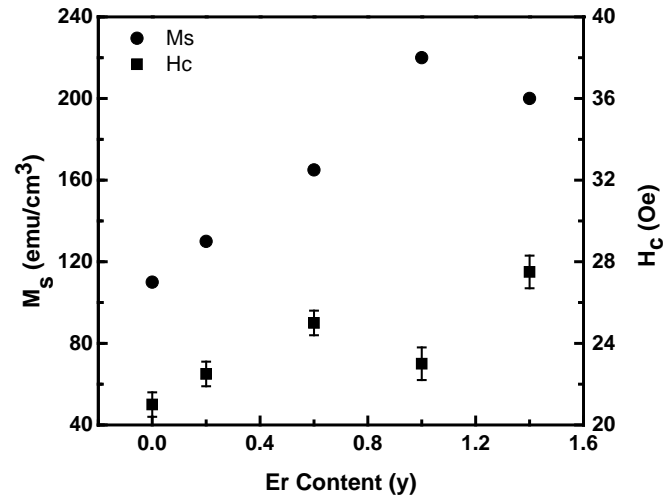

Figure 4. The variation of $\mathrm{M}_{\mathrm{s}} \& \mathrm{H}_{\mathrm{c}}$ with Er content (y).

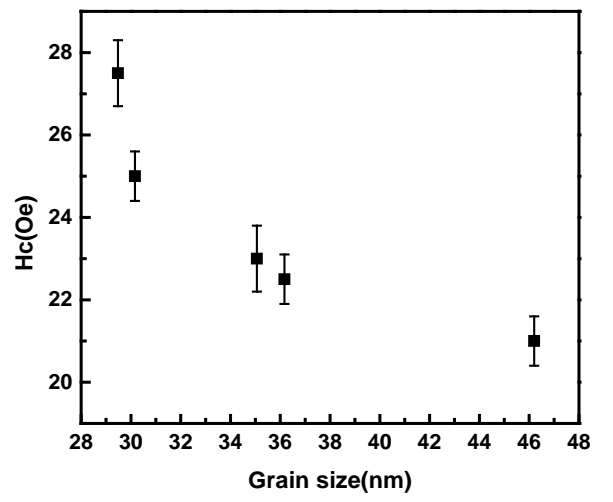

Figure 5. The variation of $\mathrm{H}_{\mathrm{c}}$ with grain size.

\subsection{Surface Morphology Characterization}

All samples were coated with a thin layer of platinum (Pt) using plasma sputtering device to overcome the electrostatic charging during characterization. Figure 6 (a-f) shows the microstructure obtained from FESEM at magnification of X50 000. The small white grains on the surface belong to Pt element. All films exhibitthe formation of agglomeration which contain nanoparticle. The estimated average grain sizes using the Smart TIFF software are in the range of $(29-46 \mathrm{~nm})$. The grain size changes unsystematically with the Er content.
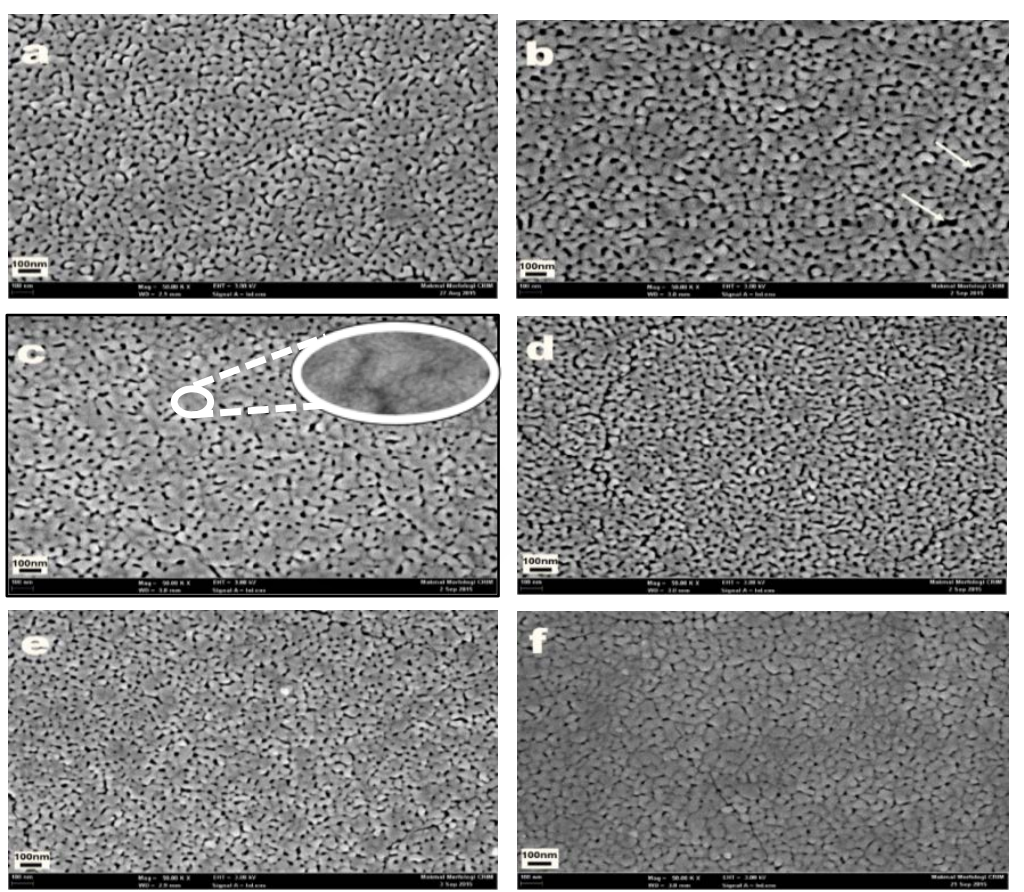

Figure 6. FE-SEM micrographs of $\mathrm{Y}_{3-\mathrm{x}-\mathrm{y}} \mathrm{Tb}_{\mathrm{x}} \mathrm{Er}_{\mathrm{y}} \mathrm{Fe}_{5} \mathrm{O}_{12}$ films: a ( $\left.\mathrm{x}=0.0, \mathrm{y}=0.0\right), \mathrm{b}(\mathrm{x}=0.2, \mathrm{y}=0.0), \mathrm{c}(\mathrm{x}=0.2, \mathrm{y}=0.2), \mathrm{d}$ $(\mathrm{x}=0.2, \mathrm{y}=0.6), \mathrm{e}(\mathrm{x}=0.2, \mathrm{y}=1.0)$ and $\mathrm{f}(\mathrm{x}=0.2, \mathrm{y}=1.4)$. The arrow sign shows the voids formation and the circle shows the agglomeration. 
The cross section backscattered FE-SEM microstructure was used to measure the film thickness as shown in Figure 7. Even though the preparation parameters were kept the same, the fluctuations of thickness with (y) content can be observed in a non-systematic way which attributed to agglomeration and annealing temperature. The thickness values of obtained films were measured in the range from 122 to $217 \mathrm{~nm}$. However, a good adhesion of the film to the substrate can be observed in Figure 7.

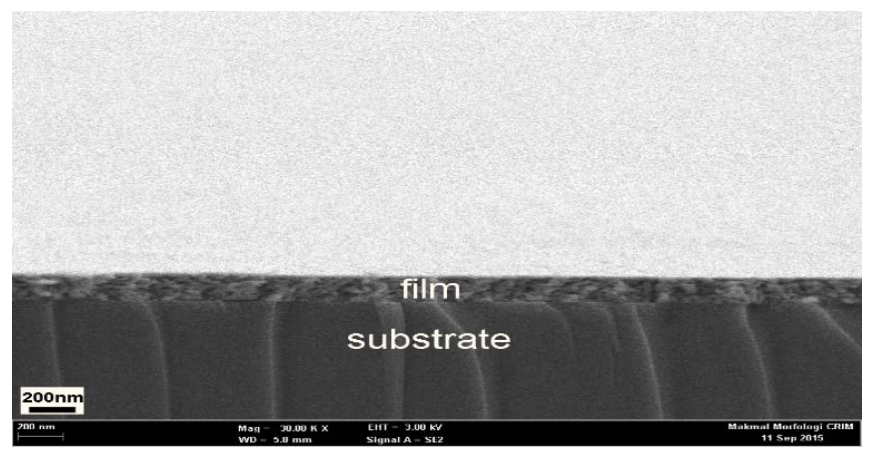

Figure 7. The typical cross-sectional image of $\mathrm{Y}_{3-\mathrm{x}-\mathrm{y}} \mathrm{Tb}_{\mathrm{x}} \mathrm{Er}_{\mathrm{y}} \mathrm{Fe}_{5} \mathrm{O}_{12}$ films.

The EDX analysis results of sample with $\mathrm{y}=0$ and 1.4, are illustrated in Figure 8. All peaks of the elements of $\mathrm{Tb}, \mathrm{Er}, \mathrm{Y}, \mathrm{Fe}$ and $\mathrm{O}$ appear on the spectrum as well as the Si peak which belongs to the quartz substrate . This result reveals that both the Er and Tb ions are introduced into YIG structure as confirmed by XRD analysis.
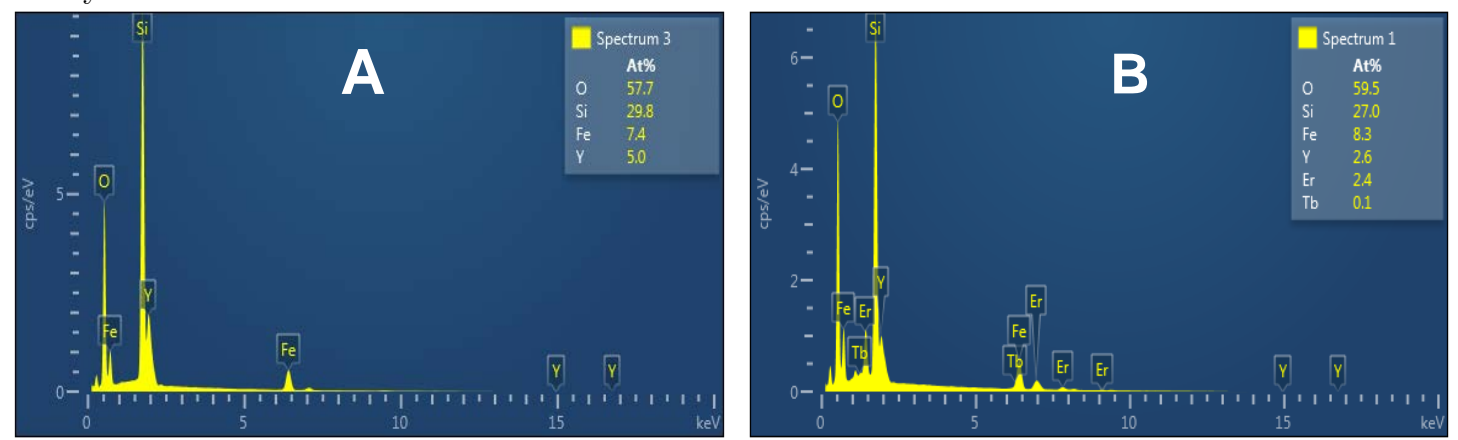

Figure 8. The typical EDX spectroscopy spectrum of $\mathrm{Y}_{3-\mathrm{x}-\mathrm{y}} \mathrm{Tb}_{\mathrm{x}} \operatorname{Er}_{\mathrm{y}} \mathrm{Fe}_{5} \mathrm{O}_{12}$ films. $\mathrm{A}(\mathrm{y}=0)$ and $\mathrm{B}(\mathrm{y}=1.4)$.

\subsection{Optical properties}

The optical transmittance spectra of obtained films at different (y) contents is shown in figure 9. All the samples are highly transparent in the visible and near infrared regions. The $\mathrm{Tb}^{3+}$ ions doped YIG reduce the optical transparency from $85 \%$ to $65 \%$. This reduction, compared to pure YIG, could be attributed to the difference in grain size and thickness. The transmittance improves (above 97\%) when $\mathrm{Er}^{3+}$ ions were doped into $\mathrm{Y}_{3-\mathrm{x}} \mathrm{Tb}_{\mathrm{x}} \mathrm{Fe}_{5} \mathrm{O}_{12}(\mathrm{y}=0.6)$, at near infrared region. The film is the thinnest film $(122.8 \mathrm{~nm})$ compared to other films. The slight reduction in transparency_of the sample $(y=1.4)$ which has the smallest grain size is mainly due to reflection losses [39]. However, the obtained results are higher than the result reported (90\%) 
by Ftema et al. [17]. As a result of the high optical transparency, the surface reflection losses were negligible. One of the main reasons for this high transparency could be attributed to reduction of light scattering from a smaller grain size $(y=0.2,0.6,1.0$ and 1.4), at visible and near infra-red region. The optical absorption coefficient $(\alpha)$ measured from the film's optical transmission spectra using the Beer - Lambert's law.

$$
\alpha=-(\ln T / t)
$$

where $T$ is transmittance and $t$ is film thickness. The change of absorption coefficient against wavelength with different y content was shown in Figure 10. In general, at a short wavelength $(\lambda<400 \mathrm{~nm})$, absorption coefficient $\alpha$ increases linearly with increment of $\mathrm{Er}^{3+}$ ions. This is because probably of electronic transitions of $\mathrm{Fe}^{3+}$ cations in octahedral and tetrahedral sites as well as a charge transfer process between $\mathrm{Fe}^{3+}$ (3d orbit) and $\mathrm{O}^{2-}\left(2 \mathrm{p}\right.$ orbit) ions, which affected by the presence of $\mathrm{Er}^{3+}$ ions [40, 41]. The absorption coefficient becomes lower at visible region, then vanishes in the near infrared, which attributed to crystal field transitions.

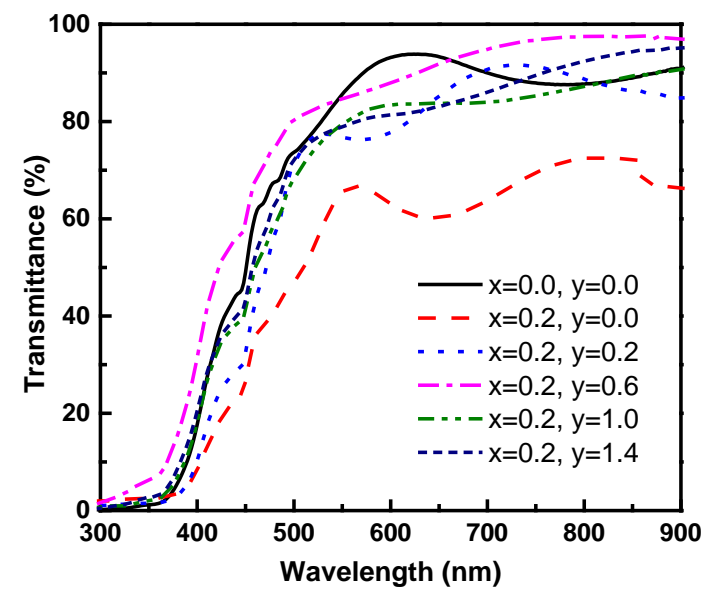

Figure 9.The optical transmission spectra of $\mathrm{Y}_{3-\mathrm{x}-\mathrm{y}} \mathrm{Tb}_{\mathrm{x}}$

$$
\mathrm{Er}_{\mathrm{y}} \mathrm{Fe}_{5} \mathrm{O}_{12} \text { films. }
$$

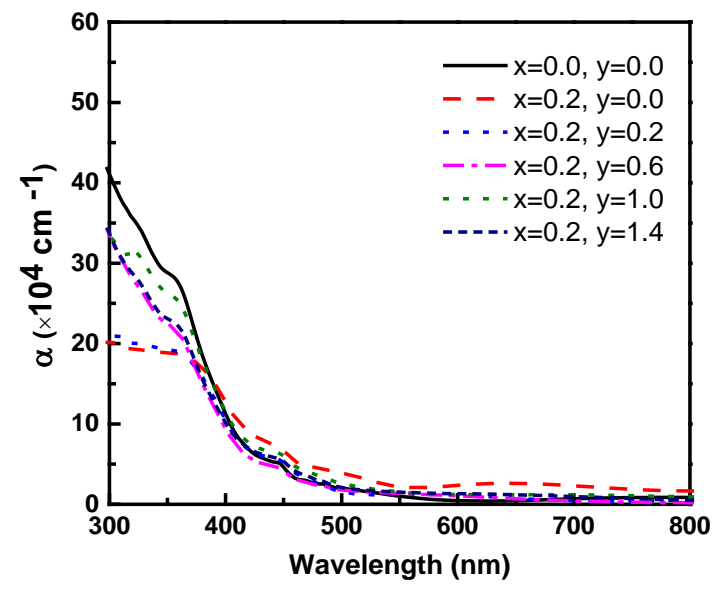

Figure 10. Absorption coefficient of Y3-x-y Tbx Ery Fe5 O12 films.

\section{Conclusion}

The nanoparticles films with the formula of $\mathrm{Y}_{3-\mathrm{x}-\mathrm{y}} \mathrm{Tb}_{\mathrm{x}} \mathrm{Er}_{\mathrm{y}} \mathrm{Fe}_{5} \mathrm{O}_{12}(\mathrm{x}=0.0,0.2)$ and $(0 \leqslant \mathrm{y} \leqslant 1.4)$ were successfully prepared using the sol-gel method. The XRD patterns revealed the cubic structure with single phase of pure garnet. The annealing temperature at $900{ }^{\circ} \mathrm{C}$ was adequate temperature to crystalline the films. A slight shift has been observed of the main peaks of XRD pattern to higher diffraction angles due to the incorporation of Er and Tb ions into YIG structure. Generally, higher saturation magnetizations of all films comparing to bulk YIG were reported. These results for such mixed garnet could be understood according to the cation distribution in YIG structure. In terms of hysteresis behavior, the films as a soft materials make them a good candidate for microwave applications. The surface morphology of the obtained films showed an average grain size around $(29-46 \mathrm{~nm})$ with a homogenous structure. Adding Er ${ }^{3+}$ ions increases the transparency from $65 \%$ to $97 \%$ at the visible and near infrared region. The small optical coefficient $\alpha\left(\right.$ in $\left.\mathrm{cm}^{-1}\right)$ in the wavelength region $(>800 \mathrm{~nm}$ ) enabling the films to be applicable to the optical isolator. 
Acknowledgement. This work was financially supported by the Malaysian Ministry of Science and technology under grant No.DLP-2014-006.

\section{References}

1. P. Fechine, F. Pereira, M. Santos, A. de Menezes, R. de Oliveira, J. Góes, et al., "Microstructure and magnetodielectric properties of ferrimagnetic composite GdIGX: YIG 1- X at radio and microwave frequencies," Journal of Physics and Chemistry of Solids, vol. 70, pp. 804-810, 2009.

2. L. GUO, H. YUAN, K. HUANG, L. YUAN, S. LIU, and S. FENG, "Hydrothermal Synthesis, Characterization and Magnetic Properties of Rare Earth Iron Garnets Sm3Fe5O12 and Eu3Fe5O12," Chem. Res. Chinese. U, vol. 27, pp. 715-719, 2011.

3. M. Pardavi-Horvath, "Microwave applications of soft ferrites," Journal of Magnetism and Magnetic Materials, vol. 215-216, pp. 171-183, 6/2/ 2000.

4. A. Goldman, Modern ferrite technology: Springer Science \& Business Media, 2006.

5. M. Deb, E. Popova, A. Fouchet, and N. Keller, "Magneto-optical Faraday spectroscopy of completely bismuthsubstituted Bi3Fe5O12 garnet thin films," Journal of Physics D: Applied Physics, vol. 45, p. 455001, 2012.

6. H. Dötsch, N. Bahlmann, O. Zhuromskyy, M. Hammer, L. Wilkens, R. Gerhardt, et al., "Applications of magnetooptical waveguides in integrated optics: review," JOSA B, vol. 22, pp. 240-253, 2005.

7. N. Yahya, R. A. Masoud, H. Daud, A. A. Aziz, and H. M. Zaid, "Synthesis of Al3Fe5O12 cubic structure by extremely low sintering temperature of sol gel technique," American Journal of Engineering and Applied Sciences, vol. 2, p. 76, 2009.

8. S. Geller and M. Gilleo, "The crystal structure and ferrimagnetism of yttrium-iron garnet, Y 3 Fe 2 (FeO 4) 3," Journal of Physics and Chemistry of Solids, vol. 3, pp. 30-36, 1957.

9. T.-C. Mao and J.-C. Chen, "Influence of the addition of CeO 2 on the microstructure and the magnetic properties of yttrium iron garnet ceramic," Journal of magnetism and magnetic materials, vol. 302, pp. 74-81, 2006.

10. A. D. Block, P. Dulal, B. J. Stadler, and N. C. Seaton, "Growth Parameters of Fully Crystallized YIG, Bi: YIG, and Ce: YIG Films With High Faraday Rotations," Photonics Journal, IEEE, vol. 6, pp. 1-8, 2014.

11. O. Galstyan, H. Lee, A. Babajanyan, A. Hakhoumian, B. Friedman, and K. Lee, "Magneto-optical visualization by Bi:YIG thin films prepared at low temperatures," Journal of Applied Physics, vol. 117, p. 6, Apr 2015.

12. A. Kehlberger, K. Richter, M. C. Onbasli, G. Jakob, D. H. Kim, T. Goto, et al., "Enhanced Magneto-optic Kerr Effect and Magnetic Properties of CeY2Fe5O12 Epitaxial Thin Films," Physical Review Applied, vol. 4, p. 10, Jul 2015 .

13. M. Nur-E-Alam, M. Vasiliev, V. Kotov, and K. Alameh, "Recent developments in magneto-optic garnet-type thinfilm materials synthesis," Procedia Engineering, vol. 76, pp. 61-73, 2014.

14. M. C. Onbasli, T. Goto, X. Sun, N. Huynh, and C. Ross, "Integration of bulk-quality thin film magneto-optical cerium-doped yttrium iron garnet on silicon nitride photonic substrates," Optics express, vol. 22, pp. 25183-25192, 2014.

15. P. P. S. Ortega, M. A. Ramirez, C. R. Foschini, F. G. Garcia, M. Cilense, and A. Z. Simões, "Synthesis, structure and magnetic properties of Y3Fe5-xAlxO12 garnets prepared by the soft chemical method," Processing and Application of Ceramics, vol. 8, pp. 211-218, 2014.

16. K. Sadhana, S. R. Murthy, and K. Praveena, "Structural and magnetic properties of Dy $3+$ doped Y 3 Fe 5 O 12 for microwave devices," Materials Science in Semiconductor Processing, vol. 34, pp. 305-311, 2015.

17. F. W. Aldbea, N. Ibrahim, and M. Yahya, "Effect of adding aluminum ion on the structural, optical, electrical and magnetic properties of terbium doped yttrium iron garnet nanoparticles films prepared by sol-gel method," Applied Surface Science, vol. 321, pp. 150-157, 2014. 
18. A. V. Svalov, V. O. Vas'kovskiy, G. V. Kurlyandskaya, J. M. Barandiaran, I. Orue, N. N. Schegoleva, et al., "Structural Peculiarities and Magnetic Properties of Nanoscale Terbium in Tb/Ti and Tb/Si Multilayers," Chinese Physics Letters, vol. 23, p. 196, 2006.

19. L. Walker, "Ferromagnetic Resonance in Terbium-Doped Yttrium Iron Garnet," Journal of Applied Physics, vol. 33, pp. 1243-1247, 1962.

20. M. Huang and S. Zhang, "A new Bi-substituted rare-earth iron garnet for a wideband and temperature-stabilized optical isolator," Journal of Materials Research, vol. 15, pp. 1665-1668, 2000.

21. R. K. Nachimuthu, R. D. Jeffery, M. Martyniuk, R. C. Woodward, P. J. Metaxas, J. M. Dell, et al., "Investigation of Cerium-Substituted Europium Iron Garnets Deposited by Biased Target Ion Beam Deposition," Magnetics, IEEE Transactions on, vol. 50, pp. 1-7, 2014.

22. M. C. Sekhar and M. R. Singh, "Fabrication and characterization of Bismuth-Cerium composite iron garnet epitaxial films for magneto optical applications," Journal of Applied Physics, vol. 112, p. 083525, 2012.

23. H. Xu and H. Yang, "Magnetic properties of YIG doped with cerium and gadolinium ions," Journal of Materials Science: Materials in Electronics, vol. 19, pp. 589-593, 2008.

24. C. Kittel, P. McEuen, and P. McEuen, Introduction to solid state physics vol. 8: Wiley New York, 1976.

25. L. Lau, N. Ibrahim, and H. Baqiah, "Influence of precursor concentration on the structural, optical and electrical properties of indium oxide thin film prepared by a sol-gel method," Applied Surface Science, vol. 345, pp. 355-359, 2015.

26. Y.-P. Fu, "Electrical conductivity and magnetic properties of Li 0.5 Fe 2.5- x Cr x O 4 ferrite," Materials Chemistry and Physics, vol. 115, pp. 334-338, 2009.

27. N. Ibrahim, F. W. Aldbea, and M. Hj Abdullah, "Effects of annealing temperature on structure and magnetic properties of Tb x Y 3-x Fe 5 O 12 ( $\mathrm{x}=0.2$ and 0.4) thin films," Journal of Nanomaterials, vol. 2012, p. $2,2012$.

28. V. K. Pecharsky and P. Y. Zavalij, Fundamentals of powder diffraction and structural characterization of materials vol. 69: Springer, 2009.

29. R. t. Shannon and C. T. Prewitt, "Effective ionic radii in oxides and fluorides," Acta Crystallographica Section B: Structural Crystallography and Crystal Chemistry, vol. 25, pp. 925-946, 1969.

30. R. Sanchez, J. Rivas, P. Vaqueiro, M. Lopez-Quintela, and D. Caeiro, "Particle size effects on magnetic properties of yttrium iron garnets prepared by a sol-gel method," Journal of magnetism and magnetic materials, vol. 247, pp. 9298, 2002.

31. W. R. Eppler and M. H. Kryder, "Garnets for short wavelength magneto-optic recording," Journal of Physics and Chemistry of Solids, vol. 56, pp. 1479-1490, 1995.

32. R. Shaiboub, N. B. y. Ibrahim, M. Abdullah, and F. Abdulhade, "The Physical Properties of Erbium-Doped Yttrium Iron Garnet Films Prepared by Sol-Gel Method," Journal of Nanomaterials, 2012.

33. R. E. Shaiboub and N. B. Ibrahim, "Characterization of Erbium Substituted Yttrium Iron Garnet Films Prepared by Sol-Gel Method," Journal of Nanoscience, vol. 2014, 2014.

34. D. Aoki and M. Shima, "Magnetic and fluorescence properties of cerium-doped yttrium gadolinium aluminum iron garnet crystals," Japanese Journal of Applied Physics, vol. 53, p. 113001, 2014.

35. G. Rowlands, "The variation of coercivity with particle size," Journal of Physics D: Applied Physics, vol. 9, p. 1267, 1976 .

36. S. Verma, S. Pradhan, R. Pasricha, S. Sainkar, and P. Joy, "A Novel Low-Temperature Synthesis of Nanosized NiZn Ferrite," Journal of the American Ceramic Society, vol. 88, pp. 2597-2599, 2005.

37. K. Kamala Bharathi, N. Kalidindi, and C. Ramana, "Grain size and strain effects on the optical and electrical properties of hafnium oxide nanocrystalline thin films," Journal of Applied Physics, vol. 108, p. 3529, 2010.

38. M. Moriyama, K. Matsunaga, T. Morita, S. Tsukimoto, and M. Murakami, "The effect of strain distribution on abnormal grain growth in Cu thin films," Materials transactions, vol. 45, pp. 3033-3038, 2004.

39. N. B. Ibrahim, C. Edwards, and S. B. Palmer, "Pulsed laser ablation deposition of yttrium iron garnet and ceriumsubstituted YIG films," Journal of Magnetism and Magnetic Materials, vol. 220, pp. 183-194, 10// 2000. 
40. P. Hansen and J.-P. Krumme, "Magnetic and magneto-optical properties of garnet films," Thin solid films, vol. 114, pp. 69-107, 1984.

41. G. Scott and J. Page, "The absorption spectra of Y3Fe5O12 and Y3Ga5O12: Fe3+ to 5.5 eV," physica status solidi (b), vol. 79, pp. 203-213, 1977. 